\title{
Anxiety and depression among chronic obstructive pulmonary disease patients in a tertiary care hospital, Nepal
}

\author{
Roka $\mathrm{T}^{1}$, Aryal $\mathrm{N}^{1}$, Ghimire $\mathrm{A}^{1}$, Pradhan $\mathrm{S}^{1}$, Aryal $\mathrm{KK}^{2}$
}

${ }^{1}$ Tara Roka, Lecturer; Nirmala Aryal, Lecturer; Anjana Ghimire, BNS Student; Subhadra Pradhan, Associate Professor; College of Nursing, Nepalese Army Institute of Health Sciences, Kathmandu, Nepal; ${ }^{2}$ Krishna Kumar Aryal, Researcher, Institute of Clinical Medicine, University of Oslo, Oslo, Norway

\begin{abstract}
Background: Psychiatric co-morbidities such as anxiety and depression among patients with chronic obstructive pulmonary disease exacerbate the disease, prolong the hospital stay, increase the disease symptoms and deter the quality of life.

Objective: To assess the proportion of anxiety or depression among patients with chronic obstructive pulmonary disease in a tertiary care hospital.

Methodology: We carried out a cross sectional study interviewing 307 patients from a tertiary care hospital using sequential sampling technique. We used structured questionnaire and included hospital anxiety and depression scale to measure anxiety and depression. We considered a summed score of $\geq 11$ on each of the subscale as a case-ness of anxiety and/or depression. We present the results as proportion and adjusted odds ratio with $95 \%$ confidence interval.

Results: We found $31 \%$ of the patients as having anxiety and 35\% having depression, with $19 \%$ of co-morbidity. We found higher odds of anxiety among certain groups: female (adjusted odds ratio - 1.93, 95\%Cl: 1.10-3.39), participants visiting doctor or health facility to manage their first episode of illness (adjusted odds ratio - 2.56, 95\%Cl: 1.35-4.87). Also, the latter group had higher odds (adjusted odds ratio - 3.57, 95\% Cl: 1.54-8.29) of co-morbid anxiety and depression. Conclusion: We found a substantial proportion of participants with case-ness of anxiety and depression. Psychiatric evaluation and additional management of these associated comorbidities could make the management of chronic obstructive pulmonary disease comprehensive and would improve quality of life of such patients.
\end{abstract}

Key words: Anxiety, Chronic Obstructive Pulmonary Disease, Depression, Hospital Anxiety and Depression Scale, Nepal, Tertiary Care Hospital

\section{INTRODUCTION}

$\mathrm{P}$ sychiatric co-morbidities, chiefly, anxiety and depression are common among the patients with chronic obstructive pulmonary disease (COPD) which increase the duration of symptoms as well as the disease course ${ }^{1}$. Experience of severe shortness of breath is likely to contribute anxiety whereas loss and grief related with the disability due to COPD may lead to depression ${ }^{2}$. Studies have even suggested that the presence of shortness of breath and exacerbation of symptoms contributes to depression, which is the most important determinant to impair health related quality of life ${ }^{3}$. Patients with increased levels of anxiety and

Address for correspondence

Krishna Kumar Aryal,

Researcher, University of Oslo, Oslo, Norway

E-mail:krish.aryal@gmail.comkrish.aryal@gmail.com depression may in turn have severe symptoms of COPD, high exacerbation rates, increased hospital stay and poor quality of life ${ }^{4,5}$. Several studies have concluded that the prevalence of anxiety and depression is high among COPD patients with females more prone to such psychological states ${ }^{6}$. Anxiety \& depression among general Nepalese population have been reported to be $16.1 \% \& 4.2 \%$ respectively $^{7}$, while one of the hospital based study reported more than one third of COPD patients having severe levels of anxiety and depression ${ }^{8}$. Evidences around common mental illnesses such as anxiety and depression is scarce even among general population as well as people with chronic illnesses in the country context. We thus aimed at exploring the proportion of COPD patients suffering from anxiety and depression and its associated factors at a tertiary care hospital in Kathmandu, Nepal. This is expected to add knowledge to the existing science to underscore 
the burden of common mental illnesses among the people living with chronic illness and would guide for comprehensive management of people with chronic illness.

\section{METHODOLOGY}

We carried out a hospital based cross sectional study in Shree Birendra Hospital, Kathmandu among 307 patients of COPD enrolled through sequential sampling. We obtained ethical approval from Institutional Ethical Review Committee of Nepalese Army Institute of Health Sciences as well as written permission from the administration of Shree Birendra hospital, and written informed consent from each study participant.

We enrolled consecutive patients meeting the criteria, those with physician confirmed diagnosis of COPD for $\geq$ one year, in the study. We interviewed patients visiting the chest OPD of the hospital through a face to face interview using semi structured questionnaire from February to March 2017. We used Hospital Anxiety and Depression scale (HADS) to assess anxiety and depression which contains 14 items in two subscales: anxiety (HADS-A) and depression (HADS-D), each with seven items (A1 to A7; D1 to D7) 9 . The Nepalese version of HADS validated in one of the tertiary care hospital in Nepal was used ${ }^{10}$.

We entered the data using EpiData Version 3.1, cleaned \& managed it in SPSS 24.0, and analysed it using STATA SE 14. We present the descriptive results as proportions with $95 \% \mathrm{Cl}$ and inferential statistics as adjusted odds ratio (aOR) through multivariate logistic regression. The variables used for adjustment in the regression analysis were sex, age, ethnicity, religion, education, marital status, the way COPD was managed in its first episode, and whether hospital admission was required in the first episode of COPD. We first carried out binary logistic regression with a single covariate for both dependent variables (anxiety and depression), followed by multivariate logistic regression to determine the associated factors for anxiety and depression. We included individual independent variables having an association with the dependent variable in univariate binary logistic regression with $p$ value $<0.25^{11}$ in the multivariate logistic regression model.

HADS rates each item on a four-point scale from 0-3 where 3 indicates maximum symptom severity and when the scores are summed the possible scores ranged from 0 to 21 for each of the subscale - anxiety and depression. A score of $\geq 11$ out of the summed score of each of the subscale - HADS-A and HADS-D indicates case-ness ${ }^{9,12}$ and is the definition of anxiety and depression which we have used in this study.

\section{RESULTS}

\section{BACKGROUND CHARACTERISTICS OF THE PARTICIPANTS}

Table 1 gives the overview of the background characteristics of COPD patients interviewed and distribution of the independent variables used in this study. In terms of age group, majority (58\%) of the participants were aged 60 to 74 years. With regards to ethnicity, more than two third (69\%) of the participants belonged to upper caste groups, while the remaining $31 \%$ were Dalits and Janajatis, the marginalised ethnic groups in the country. A clear majority of the participants (94\%) followed Hinduism as the religion, while the rest following other religions (Christianity, Buddhism, and Muslim). In terms of education, most of the participants (87\%) were illiterate or had informal schooling. Just above two third (70\%) of the participants were currently married, while the remaining $31 \%$ were either separated/ divorced/widowed.

\section{ILLNESS RELATED CHARACTERISTICS}

We found that about two-thirds (66\%) of the participants visited a doctor or a health facility for managing their first episode of illness while the rest chose home remedy or had spontaneous control of the condition. More than three quarters $(78 \%)$ did not require admission in the first episode of illness. We found that shortness of breath $(92 \%)$ and cough $(80 \%)$ were the common symptoms during early days of illness (Table 2). The median duration of illness was 7 years (Interquartile range: 9 years)

\section{PROPORTION OF PARTICIPANTS WITH ANXIETY, DEPRESSION AND CO-MORBIDITY}

We found that $31 \%$ of the participants had anxiety. Of the COPD patients interviewed, more females (39\%) than males (21\%) had anxiety. We also found that occurrence of anxiety increased with age, with $36 \%$ of participants in the age group 75 years and above having the condition. Slightly higher proportion of participants from upper caste groups (33\%) had anxiety compared to Dalits \& Janajatis (27\%). Similarly, proportion of anxiety was higher among those with Hindu religion (31\%), those with illiterate or informal schooling (33\%), those Separated/Divorced/Widowed (41\%), those who had to visit doctor/health facility in their first episode of illness $(38 \%)$, and those who required hospital admission in their first episode of illness (46\%) (Table 3). 
We found an overall $35 \%$ of the participants with depression. Slightly higher proportion of females (37\%) had depression compared to males (33\%). Similar to anxiety, occurrence of depression was the highest (38\%) among 75 years and above age participants. Occurrence of depression was not different by ethnic groups, and was similar among participants following Hinduism and other religion. Occurrence of depression decreased with education. Slightly higher proportion of separated/divorced/widowed participants had (39\%) depression compared to the currently married (34\%). We found higher proportion (39\%) of depression among participants who managed their first episode of illness by visiting a doctor or health facility compared to those with first episode of illness having had spontaneouslycontrolled or managed with home remedy. And, we also found a similar proportion (43\%) among those who required hospital admission in their first episode of illness (Table 3).

We found an overall 19\% of the participants with comorbid anxiety and depression. Slightly more males (17\%) than females (11\%) had comorbid anxiety and depression. Comorbidity slightly increased with increasing age of the participants. We found that occurrence of comorbid anxiety and depression was similar between upper caste groups and other ethnic groups. We found a slightly higher proportion (19\%) of participants with comorbid anxiety and depression compared to participants from other religion. Like anxiety and depression occurrence of co-morbidity decreased with education. Higher proportion (25\%) of separated/widowed/divorced participants had comorbid anxiety and depression. We found that, higher proportion (25\%) of participants who managed their first episode of illness by visiting a doctor or health facility had comorbid anxiety and depression compared to those with first episode of illness having had spontaneouslycontrolled or managed with home remedy (8\%). Also, higher proportion (30\%) of participants who required hospital admission in their first episode of illness had comorbid anxiety and depression (Table3).

\section{FACTORS ASSOCIATED WITH ANXIETY, DEPRESSION AND CO-MORBIDITY}

While in the multivariate analysis we found that the female participants had nearly two times higher odds of having anxiety compared to males. The participants visiting doctor or health facility in their first episode of illness had two and half times higher odds of having anxiety compared to those who managed their first episode of illness using home remedy or had it spontaneously-controlled (Table 4).

On the other hand, the participants visiting doctor or health facility in their first episode of illness also had three and half times higher odds of having comorbid anxiety \& depression compared to those who managed their first episode of illness using home remedy or had it spontaneously -controlled (Table 4).

\section{Table 1: Background Characteristics}

\begin{tabular}{|c|c|c|c|}
\hline Variables & Categories & $\mathbf{n}$ & $\%$ \\
\hline \multirow{2}{*}{$\operatorname{Sex}(n=307)$} & Male & 140 & 45.6 \\
\hline & Female & 167 & 54.4 \\
\hline \multirow{3}{*}{ Age Group in Years $(n=307)$} & 45 to 59 & 48 & 15.6 \\
\hline & 60 to 74 & 179 & 58.3 \\
\hline & 75 and above & 80 & 26.1 \\
\hline \multirow{2}{*}{ Ethnicity* $(n=306)$} & Upper Caste Groups & 212 & 69.3 \\
\hline & Dalits and Janajatis & 94 & 30.7 \\
\hline \multirow{2}{*}{ Religion ( $n=307$ ) } & Hindu & 287 & 93.5 \\
\hline & Other Religion & 20 & 6.5 \\
\hline \multirow{2}{*}{ Education $(n=307)$} & Illiterate and Informal Schooling & 267 & 87.0 \\
\hline & Formal Schooling & 40 & 13.0 \\
\hline \multirow{2}{*}{ Marital status $(\mathrm{n}=305)^{\#}$} & Currently Married & 212 & 69.5 \\
\hline & Separated/Widowed/Divorced & 93 & 30.5 \\
\hline
\end{tabular}

* 1 Case in 'other' ethnic category excluded

\# 2 cases had missing values in marital status 
Roka T et al.

Table 2: Illness related characteristics $(\mathrm{N}=307)$

\begin{tabular}{|c|c|c|c|}
\hline Variables & Category & $\mathbf{n}$ & $\%$ \\
\hline \multirow[t]{2}{*}{ Management of illness in its first episode } & Spontaneously controlled/home remedy & 105 & 34.2 \\
\hline & Visited Doctor/Health Facility & 202 & 65.8 \\
\hline \multirow[t]{2}{*}{ Hospital admission required in first episode of illness } & Yes & 67 & 21.8 \\
\hline & No & 240 & 78.2 \\
\hline \multirow[t]{6}{*}{ Initial sign and symptoms* } & Shortness of breath & 279 & 91.5 \\
\hline & Cough & 245 & 80.3 \\
\hline & Chest pain & 45 & 14.8 \\
\hline & Fever & 27 & 8.9 \\
\hline & Chest tightness & 10 & 3.3 \\
\hline & Others & 13 & 4.3 \\
\hline
\end{tabular}

* Multiple response

Table 3: Proportion of Anxiety, Depression and Co-Morbid Anxiety Depression

\begin{tabular}{|c|c|c|c|c|c|c|c|}
\hline & \multirow{2}{*}{$\begin{array}{c}\mathbf{n} \\
307\end{array}$} & \multicolumn{2}{|c|}{ Anxiety } & \multicolumn{2}{|c|}{ Depression } & \multicolumn{2}{|c|}{ Co Morbid Anxiety \& Depression } \\
\hline & & $\%$ & $95 \% \mathrm{Cl}$ & $\%$ & $95 \% \mathrm{Cl}$ & $\%$ & $95 \% \mathrm{Cl}$ \\
\hline \multicolumn{8}{|l|}{ Sex } \\
\hline Male & 140 & 20.7 & $14.8-28.3$ & 32.9 & $25.5-41.1$ & 13.6 & $8.8-20.4$ \\
\hline Female & 167 & 38.9 & $31.8-46.6$ & 37.1 & $30.1-44.8$ & 23.4 & $17.5-30.4$ \\
\hline \multicolumn{8}{|l|}{ Age Groups (Years) } \\
\hline 45 to 59 & 48 & 29.2 & $18.0-43.6$ & 33.3 & $21.4-47.9$ & 20.8 & $11.5-34.8$ \\
\hline 60 to 74 & 179 & 28.5 & $22.3-35.6$ & 34.6 & $28.0-41.9$ & 17.3 & $12.4-23.6$ \\
\hline 75 and above & 80 & 36.3 & $26.4-47.4$ & 37.5 & $27.5-48.7$ & 21.3 & $13.6-31.7$ \\
\hline \multicolumn{8}{|l|}{ Ethnicity* } \\
\hline Upper Caste Groups & 212 & 32.5 & $26.5-39.2$ & 34.0 & $27.9-40.6$ & 18.4 & $13.7-24.2$ \\
\hline Dalit \& Janajatis & 94 & 26.6 & $18.6-36.5$ & 38.3 & $29.0-48.6$ & 20.2 & $13.2-29.6$ \\
\hline \multicolumn{8}{|l|}{ Religion } \\
\hline Hindu & 287 & 31.4 & $26.2-37.0$ & 35.2 & $29.9-40.9$ & 19.2 & $15.0-24.2$ \\
\hline Other Religion & 20 & 20.0 & $7.5-43.6$ & 35.0 & $17.3-58.1$ & 15.0 & $4.7-38.5$ \\
\hline \multicolumn{8}{|l|}{ Education } \\
\hline Illiterate or Informal Schooling & 267 & 33.0 & $27.6-38.9$ & 36.7 & $31.1-42.7$ & 20.6 & $16.1-25.9$ \\
\hline Formal Schooling & 40 & 15.0 & $6.8-30.0$ & 25.0 & $13.9-40.8$ & 7.5 & $2.4-21.1$ \\
\hline \multicolumn{8}{|l|}{ Marital Status $\#$} \\
\hline Currently Married & 212 & 25.9 & $20.5-32.3$ & 33.5 & $27.4-40.2$ & 16.0 & $11.7-21.6$ \\
\hline Separated/Widowed/Divorced & 93 & 40.9 & $31.3-51.2$ & 38.7 & $29.3-49.0$ & 24.7 & $17.0-34.6$ \\
\hline \multicolumn{8}{|c|}{ Management of Illness in its First Episode } \\
\hline $\begin{array}{l}\text { Spontaneously-controlled/Home } \\
\text { Remedy }\end{array}$ & 105 & 17.1 & $11.0-25.7$ & 27.6 & $19.9-27.0$ & 7.6 & $3.8-14.6$ \\
\hline Visited Doctor/Health Facility & 202 & 37.6 & $31.2-44.5$ & 39.1 & $32.6-46.1$ & 24.8 & 19.3-31.2 \\
\hline \multicolumn{8}{|c|}{ Hospital Admission required in first episode of illness } \\
\hline Yes & 67 & 46.3 & $34.6-58.3$ & 43.3 & $31.9-55.4$ & 29.9 & $20.0-41.9$ \\
\hline No & 240 & 26.3 & $21.0-32.2$ & 32.9 & 27.2-39.1 & 15.8 & $11.7-21.0$ \\
\hline Total & 307 & 30.6 & $25.7-36.0$ & 35.2 & $30.0-40.7$ & 18.9 & $14.9-23.7$ \\
\hline
\end{tabular}

* 1 Case in 'other' ethnic category excluded

\# 2 cases had missing values in marital status 
Table 4: Factors Associated with Anxiety and Co Morbid Anxiety Depression

\begin{tabular}{|c|c|c|c|c|c|}
\hline & \multirow{2}{*}{$\begin{array}{c}\mathbf{n} \\
307\end{array}$} & \multicolumn{2}{|c|}{ Anxiety } & \multicolumn{2}{|c|}{ Co Morbid Anxiety \& Depression } \\
\hline & & Crude OR & Adjusted OR & Crude OR & Adjusted OR \\
\hline \multicolumn{6}{|l|}{ Sex } \\
\hline Male & 140 & 1 & 1 & 1 & 1 \\
\hline Female & 167 & $2.44(1.46-4.08)$ & $1.93(1.10-3.39)$ & $1.94(1.06-3.54)$ & $1.42(0.73-2.76)$ \\
\hline \multicolumn{6}{|l|}{ Age in Category } \\
\hline 45 to 59 years & 48 & 1 & NA & 1 & NA \\
\hline 60 to 74 years & 179 & $0.97(0.48-1.95)$ & NA & $0.80(0.36-1.77)$ & NA \\
\hline 75 years and above & 80 & $1.38(0.64-2.99)$ & NA & $1.03(0.43-2.47)$ & NA \\
\hline \multicolumn{6}{|l|}{ Ethnicity* } \\
\hline Upper Caste Groups & 212 & 1 & NA & 1 & NA \\
\hline Dalit \& Janajatis & 94 & $0.75(0.44-1.29)$ & NA & $1.12(0.61-2.07)$ & NA \\
\hline \multicolumn{6}{|l|}{ Religion } \\
\hline Hindu & 287 & 1 & NA & 1 & NA \\
\hline Other Religion & 20 & $0.55(0.18-1.68)$ & NA & $0.74(0.21-2.63)$ & NA \\
\hline \multicolumn{6}{|l|}{ Education } \\
\hline Formal Schooling & 40 & 1 & 1 & 1 & 1 \\
\hline Illiterate \& Informal Schooling & 267 & $2.79(1.13-6.88)$ & $1.99(0.75-5.25)$ & $3.20(0.95-10.77)$ & $2.62(0.73-9.42)$ \\
\hline \multicolumn{6}{|l|}{ Marital Status $\#$} \\
\hline Currently Married & 212 & 1 & 1 & 1 & 1 \\
\hline Separated/Widowed/Divorced & 93 & $1.97(1.18-3.30)$ & $1.75(0.99-3.09)$ & $1.72(0.95-3.13)$ & $1.60(0.83-3.06)$ \\
\hline \multicolumn{6}{|c|}{ Management of Illness in its First Episode } \\
\hline $\begin{array}{l}\text { Spontaneously-Controlled/ } \\
\text { Home Remedy }\end{array}$ & 105 & 1 & 1 & 1 & 1 \\
\hline Visited Doctor/Health Facility & 202 & $2.91(1.63-5.22)$ & $2.56(1.35-4.87)$ & $3.99(1.81-8.78)$ & $3.57(1.54-8.29)$ \\
\hline \multicolumn{6}{|c|}{ Hospital Admission required in first episode of illness } \\
\hline No & 240 & 1 & 1 & 1 & 1 \\
\hline Yes & 67 & $2.42(1.38-4.23)$ & $1.80(0.96-3.36)$ & $2.26(1.21-4.24)$ & $1.55(0.78-3.06)$ \\
\hline
\end{tabular}

*1 Case in other ethnic category excluded

\#2 Cases missing values in marital status

$\wedge$ Note: None of the independent variables were significant at the level of $p<0.25$ with depression and are not shown here in the multivariate analysis

\section{DISCUSSION}

We carried out a cross sectional hospital based study which assessed occurrence of increased levels of anxiety and depression among COPD diagnosed patients and calculated occurrence of comorbid anxiety and depression. We found one in three patients with increased levels of anxiety as well as depression. Similarly, a substantial proportion (19\%) had comorbid anxiety and depression.

The proportion of anxiety and depression is slightly lower than one of the other recent study from two hospitals in Nepal which showed more than one third of COPD patients with severe anxiety as well as depression ${ }^{8}$.
The difference could be because of the difference in study population, as the other study included only hospitalized patients, while our study participants consisted of patients in the OPD clinic in a hospital. One of the other study from the neighbouring country India from similar (OPD) settings to the current study reported a high proportion of COPD patients having both anxiety and depression $(43 \%)^{13}$. Result from the current study is however, similar to one of the earlier studies among COPD patients entering pulmonary rehabilitation in the Netherlands where $32 \%$ of participants had anxiety and $27 \%$ had depression ${ }^{14}$ and a similar proportion of COPD patients in a study from England had anxiety (33\%) and slightly lower proportion had depression $(21 \%)^{15}$. 
Furthermore, depressive symptoms have been found with higher prevalence among patients with COPD compared to those without as shown by the Singapore Longitudinal Ageing Study ${ }^{16}$ and its proportion was also shown to be significantly higher among COPD individuals (25\%) against the controls (12\%) as seen in a systematic review and meta-analysis of more than 39000 individuals each ${ }^{17}$.

The present study showed that more women (39\%) had anxiety compared to men (21\%) along with higher odds of anxiety among women post adjustment. This was in contrary with the findings from the other study on anxiety and depression among hospitalized COPD patients in Nepal where they only found a slightly higher occurrence among females ${ }^{8}$. The finding in the current study was though consistent with the findings from a hospital based study in Italy among COPD patients attending respiratory unit which showed $38 \%$ of female participants with anxiety ${ }^{6}$ and another study from Nordic countries among patients at the time of discharge after hospitalization showing $47 \%$ of women having anxiety compared to $34 \%$ in men ${ }^{18}$. Higher proportion of separated/widowed/divorced participants had anxiety as well as depression in the current study which might be due to reasons such as lack of husband's support.

Out of the factors assessed, being women, requirement of visiting a doctor/health facility, and requirement of hospitalization in the first episode of illness were found to be independently associated with anxiety. And requirement of visiting a doctor/health facility in the first episode of illness was also associated with co-morbid anxiety and depression. The associations were however not very strong. The primary focus of this study was to reveal the magnitude of common mental disorders such as anxiety and depression among COPD patients. These conditions in patients suffering with COPD cannot be ignored and needs to be considered seriously to assess and aim for a better management of the conditions ${ }^{19,20}$. Furthermore, several studies report anxiety and depression in COPD patients being more likely to cause hospitalization, affect their ability to cope with and self-manage their condition with an ultimate effect on quality of life, increase in exacerbation, increase in the risk of COPD outcomes ultimately deteriorating the patients' general condition and quality of life $\mathrm{e}^{19-21}$.
The study has a number of strengths. We have used standard and widely used instrument to measure the case-ness of anxiety and depression and the instrument was also validated in the Nepalese context. Physician confirmed COPD patients were included as the participants of the study. Some of the researchers themselves collected the data along with some research assistants. Nevertheless, there were some limitations as well. The study followed a sequential sampling and the study being carried out in just one hospital, the generalizability is limited. Though we have tried to consider some of the factors associated with anxiety and depression, the cross-sectional nature of the study does not explain causality.

\section{CONCLUSION}

A substantial proportion of patients with COPD had anxiety, depression as well as co-morbid anxiety and depression. The occurrence of anxiety, depression and co-morbidity was higher among females, those with low or no education, those separated/divorced/widowed. These common mental disorders may be associated with increased mortality, exacerbation rates, hospital admission and length of hospital stay, and decreased quality of life and functional ability. And many of these have been shown in several other studies. Thus, psychiatric evaluation of COPD patients seems very important and added treatment for these associated psychological comorbidities may improve response to COPD treatment and also enhancing the quality of life. Thus, COPD patients need to be considered for screening for anxiety and depression in clinical settings.

\section{ACIKNOWLEDGMENTS}

We would like to express our sincere gratitude to the Senior Management Team of the Birendra Hospital, Chhauni, Kathmandu for their approval in implementing this study. We are obliged to Dr. Arun Neopane from College of Medicine, Nepalese Army Institute of Health Sciences for his support in designing the study and study instruments. We acknowledge the Institutional Ethical Review Committee of the Nepalese Army Institute of Health Sciences for providing ethical clearance for the study. Finally, we sincerely acknowledge the study participants for their valuable participation in this study. 


\section{REFERENCES}

1. Chaudhary SC, Nanda S, Tripathi A, Sawlani KK, Gupta KK, Himanshu D, et al. Prevalence of psychiatric comorbidities in chronic obstructive pulmonary disease patients. Lung India. 2016;33(2):174-8. https://doi.org/10.4103/0970-2113.177441.

2. Hill K, Geist R, Goldstein RS, Lacasse Y. Anxiety and depression in end-stage COPD. Eur Respir J. 2008;31(3):667-77. https://doi. org/10.1183/09031936.00125707.

3. Burgel PR, Escamilla R, Perez T, Carre P, Caillaud D, Chanez $P$, et al. Impact of comorbidities on COPD specific health-related quality of life. Respir Med. 2013;107(2):233-41. https://doi.org/10.1016/j. rmed.2012.10.002.

4. Mehta JR, Ratnani IJ, Dave JD, Panchal BN, Patel AK, Vala AU. Association of psychiatric co-morbidities and quality of life with severity of chronic obstructive pulmonary disease. East Asian Arch Psychiatry. 2014;24(4):148-55.

5. Pumar MI, Gray CR, Walsh JR, Yang IA, Rolls TA, Ward DL. Anxiety and depression-Important psychological comorbidities of COPD. J Thorac Dis. 2014;6(11):161531.

6. Di Marco F, Verga M, Reggente M, Maria Casanova $F$, Santus P, Blasi F, et al. Anxiety and depression in COPD patients: The roles of gender and disease severity. Respir Med. 2006;100(10):1767-74. https:// doi.org/10.1016/j.rmed.2006.01.026

7. Risal A, Manandhar K, Linde M, Steiner TJ, Holen A. Anxiety and depression in Nepal: prevalence, comorbidity and associations. BMC Psychiatry. 2016;16:102. https://doi.org/10.1186/s12888-0160810-0.

8. Thapa N, Maharjan M, Shrestha TM, Gauchan S, Pun $P$, Thapa YB. Anxiety and depression among patients with chronic obstructive pulmonary disease and general population in rural Nepal. BMC Psychiatry. 2017;17(1):397. https://doi.org/10.1186/s12888-0171550-5.

9. Snaith RP. The Hospital Anxiety And Depression Scale. Health Qual Life Outcomes. 2003;1:29. https:// doi.org/10.1186/1477-7525-1-29

10. Risal A, Manandhar K, Linde M, Koju R, Steiner TJ, Holen A. Reliability and Validity of a Nepali-language Version of the Hospital Anxiety and Depression Scale (HADS). Kathmandu Univ Med J (KUMJ). 2015;13(50):115-24.

11. Alvik A, Aalen OO, Lindemann R. Early fetal binge alcohol exposure predicts high behavioral symptom scores in 5.5-year-old children. Alcohol Clin Exp
Res. 2013;37(11):1954-62. https://doi.org/10.1111/ acer.12182.

12. Zigmond AS, Snaith RP. The hospital anxiety and depression scale. Acta Psychiatr Scand. 1983;67(6):361-70. https://doi. org/10.1111/j.1600-0447.1983.tb09716.x.

13. Biswas D, Mukherjee S, Chakroborty R, Chatterjee $S$, Rath S, Das R, et al. Occurrence of Anxiety and Depression among Stable COPD Patients and its Impact on Functional Capability. J Clin Diagn Res. 2017;11(2):OC24-OC7. https://doi.org/10.7860/ JCDR/2017/24203.9393.

14. Janssen DJ, Spruit MA, Leue C, Gijsen C, Hameleers $\mathrm{H}, \mathrm{Schols} \mathrm{JM}$, et al. Symptoms of anxiety and depression in COPD patients entering pulmonary rehabilitation. Chron Respir Dis. 2010;7(3):147-57. https://doi.org/10.1177/1479972310369285.

15. Cleland JA, Lee AJ, Hall S. Associations of depression and anxiety with gender, age, health-related quality of life and symptoms in primary care COPD patients. Fam Pract. 2007;24(3):217-23. https://doi. org/10.1093/fampra/cmm009.

16. Ng TP, Niti M, Fones C, Yap KB, Tan WC. Comorbid association of depression and COPD: a populationbased study. Respir Med.2009;103(6):895901. https://doi.org/10.1016/j.rmed.2008.12.010

17. Zhang MW, Ho RC, Cheung MW, Fu E, Mak A. Prevalence of depressive symptoms in patients with chronic obstructive pulmonary disease: a systematic review, meta-analysis and meta-regression. Gen Hosp Psychiatry. 2011;33(3):217-23. https://doi. org/10.1016/j.genhosppsych.2011.03.009.

18. Gudmundsson $G$, Gislason $T$, Janson $C$, Lindberg $E$, Suppli Ulrik C, Brondum E, et al. Depression, anxiety and health status after hospitalisation for COPD: a multicentre study in the Nordic countries. Respir Med. 2006;100(1):87-93. https://doi.org/10.1016/j. rmed.2005.04.003.

19. Pooler A, Beech R. Examining the relationship between anxiety and depression and exacerbations of COPD which result in hospital admission: a systematic review. Int J Chron Obstruct Pulmon Dis. 2014;9:315-30. https://doi.org/10.2147/COPD. S53255.

20. Ninot G. [Anxiety and depression in COPD: a review]. Rev Mal Respir. 2011;28(6):739-48. https://doi. org/10.1016/j.rmr.2010.11.005.

21. Atlantis E, Fahey P, Cochrane B, Smith S. Bidirectional associations between clinically relevant depression or anxiety and COPD: a systematic review and metaanalysis. Chest. 2013;144(3):766-77. https://doi. org/10.1378/chest.12-1911. 